\title{
Tropospheric column ozone: matching individual profiles from Aura OMI and TES with a chemistry-transport model
}

\author{
Q. Tang ${ }^{1,2}$ and M. J. Prather ${ }^{1}$ \\ ${ }^{1}$ Department of Earth System Science, University of California, Irvine, California, 92697, USA \\ ${ }^{2}$ Department of Biological and Environmental Engineering, Cornell University, Ithaca, New York, 14853, USA
}

Correspondence to: Q. Tang (qtang@cornell.edu)

Received: 6 June 2012 - Published in Atmos. Chem. Phys. Discuss.: 29 June 2012

Revised: 31 October 2012 - Accepted: 5 November 2012 - Published: 8 November 2012

\begin{abstract}
Of all satellite measurements of ozone, only two instruments have coincident, spatially overlapping measurements to allow direct comparison of tropospheric column ozone (TCO): the Ozone Monitoring Instrument (OMI) and the Tropospheric Emission Spectrometer (TES) on the NASA Aura spacecraft. For two years (2005-2006), we collect all observations between $60^{\circ} \mathrm{S}$ and $60^{\circ} \mathrm{N}$ from nadir ( $\sim 65000$ from OMI and TES) and cross-track swaths $(\sim 30000000$ from OMI) and compare with a chemistrytransport model (CTM) simulating each observation with corresponding spatial and temporal coincidence. Highfrequency TCO variations are indicative of stratospheric intrusions of ozone-rich air, and the individual, level 2 data provide access to these short-lived phenomena. Although we can identify some seasonal and large-scale biases in the model, the CTM as a transfer standard identifies weaknesses in the observations and further helps quantify the measurement noise of individual profiles. The relatively noise-free CTM bridges these two satellite measurements and improves their cross-validation to better precision than a simple direct comparison. Previous validation studies of TES TCO versus ozonesondes found a bias of about +4 Dobson Units (DU) for large regions. The three-way comparison and the CTM transfer method that use a far greater number of coincidences, indicate that monthly zonal mean OMI-TES TCO biases fall within 5-10\%, and thus quantifies the zonal mean OMI TCO bias at a few DU. For small regions (i.e., $5 \times 5^{\circ}$ ), however, the monthly mean OMI-TES differences can exceed $\pm 10 \mathrm{DU}$ at many places (e.g., tropics for the direct OMI-TES comparison) due to different tropospheric sensitivities of the two instruments at these locations. Partly removing the influence of different sensitivities by applying
\end{abstract}

the CTM as the transfer standard, the OMI-TES differences generally decrease, especially over the tropics. In addition, the CTM-TES comparison split into day versus night observations shows no apparent bias in TES at very low levels, \pm 1 DU. These OMI-TES-CTM comparisons highlight the importance of the a priori ozone profiles that went into each satellite retrieval, including a false agreement due to CTM-a priori similarity, and the importance of including the vertical information (i.e., averaging kernel) in the retrieval products. This study also highlights the advantages of overlapping measurements in terms of cross-validation and the application of a model as the transfer standard.

\section{Introduction}

Among the four Earth Observing System (EOS) Aura instruments - High Resolution Dynamics Limb Sounder (HIRDLS), Microwave Limb Sounder (MLS), Ozone Monitoring Instrument (OMI), and Tropospheric Emission Spectrometer (TES) - only OMI and TES have coincident ozone $\left(\mathrm{O}_{3}\right)$ measurements through the troposphere, providing the information content and the opportunity to compare tropospheric column ozone (TCO) with these two datasets directly on a single, overlapping measurement basis as is presented here. Applying a chemistry-transport model (CTM) as the transfer standard to compare different satellite measurements provides a unique opportunity for both model and measurement validation (Zhang et al., 2010), but it brings into the comparison model errors, which are not always well understood (e.g., Eyring et al., 2010; Holmes et al., 2011). Other approaches to validate satellite data use sonde, lidar,

Published by Copernicus Publications on behalf of the European Geosciences Union. 
or aircraft measurements, but these involve few direct comparisons, often with measurements that are not closely geolocated in space or time and are not globally or seasonally representative. Direct comparison of satellite measurements provides far more samples, pairs of observations that truly overlap, and coverage that is global and continuous. A geolocated, comprehensive and representative cross-validation of satellite measurements of ozone is especially important for studies focusing on processes with high-frequency variations and short-lived features, such as tropopause folds (TFs).

It remains difficult still to compare directly the profiles of seemingly coincident satellite measurements. For example, (Tang and Prather, 2012, Figs. 3, 4, A1-A4) compared the four Aura instruments for several swaths in which a major TF was observed by the sonde and predicted by the CTM, but found that differing horizontal and vertical resolution, sensitivities, as well as offset from the nadir track made it difficult to pinpoint the TFs. OMI observes a wide cross-track swath, while TES observes a sequence of nadir spots that fall in one of the OMI pixels (see below). Even these two overlapping nadir sounders have different sensitivities to $\mathrm{O}_{3}$ at different altitudes, and their retrieved profiles of $\mathrm{O}_{3}$ abundance have fundamentally different averaging kernels (AK) and initial guess for the $\mathrm{O}_{3}$ profile (a priori). At altitudes where the observed spectrum is insensitive to the $\mathrm{O}_{3}$ abundance, the retrieved profile is predominantly the a priori. Previous studies (Rodgers and Connor, 2003; Luo et al., 2007b; Ho et al., 2009; Zhang et al., 2010) have shown that if one is to exclude the impacts of different a priori constrains and smoothing errors due to different $\mathrm{AK}$, then one must use the same a priori for both retrievals and to use equivalently coarse vertical resolution in the AK for each.

Because of the above problems in comparing and using these TCO datasets, in this study, we examine the mean biases, covariances, and monthly spatial patterns of the coincident TCO fields from Aura OMI and TES level 2 (L2) swath data as well as the University of California, Irvine (UCI) CTM. Descriptions of the model and measurements are given in Sect. 2. Section 3 describes the main results, while Sect. 4 examines day-night differences in the TES measurements. The conclusions in Sect. 5 discuss the magnitude of model bias error and measurement noise for TCO measurements.

\section{Measurements and model}

The EOS Aura satellite was launched on 15 July 2004 to a sun-synchronous polar orbit $705 \mathrm{~km}$ above the sea surface with a $98^{\circ}$ inclination. Aura is part of the A-Train and crosses the equator about 13:45 local time. Two nadirviewing, passive sounding instruments, OMI and TES, are on Aura (Schoeberl et al., 2006). OMI measures at ultraviolet and visible wavelengths (UV-1: $264-311 \mathrm{~nm}, \mathrm{UV}-2$ : $307-$ $383 \mathrm{~nm}$, VIS: 349-504 nm) (Levelt et al., 2006; OMI Team, 2009), whereas TES measures thermal emissions in the in- frared $\left(650-3250 \mathrm{~cm}^{-1}\right)$ (Osterman et al., 2009). OMI uses a 2-dimensional Charge-Coupled Device to scan a wide area (2600 km cross-orbit swath with $13 \mathrm{~km} \times 48 \mathrm{~km}$ resolution), while TES stares at a small spot ( $5 \mathrm{~km} \times 8 \mathrm{~km}$ nadir footprint) to measure the Fourier transform of the spectrum. As to the a priori $\mathrm{O}_{3}$ profiles used in the retrievals, OMI uses a latitudeby-month climatology based upon observations (McPeters et al., 2007; Kroon et al., 2011), whereas TES adopts a climatology that varies with latitude and longitude derived from the MOZART CTM (Brasseur et al., 1998; Park et al., 2004). Level 2 (L2) orbit/swath data are used in this study: the OMI OMO3PR V003 data (de Haan and Veefkind, 2009) and the TES version 4 (V004, F05_07) nadir global survey product. Although both datasets report ozone profiles, they contain only about 1-2 degrees of freedom for the signal (DOFS) in the troposphere (Nassar et al., 2008; Zhang et al., 2010), and thus provide limited profile resolution but reasonable TCO information. The tropopause heights simulated by the UCI CTM with a tropospheric-age tracer (e90) (Prather et al., 2011; Tang et al., 2011) are chosen for each satellite coincidence, and these spline-interpolated pressure levels are applied to linearly interpolated OMI and TES profiles to calculate each TCO. TES data whose "SpeciesRetrievalQuality" or "O3_Ccurve_QA" is not equal to 1 are removed based on Osterman et al. (2009).

The UCI CTM has $1 \times 1^{\circ} \times 40$-layer $\times 0.5 \mathrm{hr}$ resolution for years 2005-2006 and is driven by the pieced-forecast meteorology from the European Centre for Medium-Range Weather Forecasts (ECMWF) Integrated Forecast System developed by the University of Oslo (Kraabøl et al., 2002; Isaksen et al., 2005). The CTM includes tropospheric chemistry (Carver et al., 1997) as well as the linearized $\mathrm{O}_{3}$ chemistry (Linoz version 2) (Hsu and Prather, 2009). For further details see Prather et al. (2008); Prather and Hsu (2010); Tang and Prather (2010). Satellite tracks are stored from the simulation to match the exact timing and location of OMI and TES observations (see Tang and Prather, 2012, for details). OMI and TES data are assigned to the $1 \times 1^{\circ}$ model grid boxes that include the center point of observations. All comparisons here are made with matching pairs on the model grids.

Raw CTM profiles need to be convolved with the satellite operator (i.e., a priori and $\mathrm{AK}$ ) before comparing with satellite data following the equation (e.g. Luo et al., 2007a; Worden et al., 2007):

$\hat{\boldsymbol{x}}_{\mathrm{m}}=\boldsymbol{x}_{\mathrm{a}}+\mathbf{A}\left(\boldsymbol{x}_{\mathrm{m}}-\boldsymbol{x}_{\mathrm{a}}\right)$

where $\boldsymbol{x}_{\mathrm{a}}$ and $\mathbf{A}$ are the a priori and AK, respectively. $\boldsymbol{x}_{\mathrm{m}}$ represents the CTM profiles interpolated on satellite levels. The convolved CTM profile $\hat{\boldsymbol{x}}_{\mathrm{m}}$ then contains the contributions from the a priori and the vertical smoothing of satellite retrievals and is thus appropriate for comparison with satellite data. The CTM TCO in this study is calculated from $\hat{\boldsymbol{x}}_{\mathrm{m}}$ with linear interpolation and the modeled tropopause.

OMI and TES use different a priori profiles, thus introducing artificial differences in their retrieved profiles. To remove 
the a priori influence in direct OMI-TES comparisons, the TES a priori $\left(\boldsymbol{x}_{\mathrm{a}}^{\mathrm{TES}}\right)$ is replaced by the OMI a priori $\left(\boldsymbol{x}_{\mathrm{a}}^{\mathrm{OMI}}\right.$, interpolated to the TES pressure grid) by the equation (Rodgers and Connor, 2003; Luo et al., 2007b):

$\hat{\boldsymbol{x}}^{\mathrm{TES}}=\boldsymbol{x}^{\mathrm{TES}}+\left(\mathbf{I}-\mathbf{A}^{\mathrm{TES}}\right)\left(\boldsymbol{x}_{\mathrm{a}}^{\mathrm{OMI}}-\boldsymbol{x}_{\mathrm{a}}^{\mathrm{TES}}\right)$

where $\boldsymbol{x}^{\mathrm{TES}}$ is the original TES profile and $\hat{\boldsymbol{x}}^{\mathrm{TES}}$ is the TES retrieval with OMI a priori. $\mathbf{I}$ is a unit matrix and $\mathbf{A}^{\mathrm{TES}}$ is the TES AK. Given the limited DOFS in the troposphere, their integrated TCO is expected to be less dependent on the AK than on the a priori, and we do not adjust the retrievals due to AK differences. Some TES profiles have no AK and are dropped from this analysis.

Zhang et al. (2010) presents a theoretical framework for using a CTM as a transfer standard to compare different satellite data. The mathematical formulation is briefly reviewed as follows. The retrieved satellite profile $\hat{\boldsymbol{x}}$ can be generally written as:

$\hat{\boldsymbol{x}}=\boldsymbol{x}_{\mathrm{a}}+\mathbf{A}\left(\boldsymbol{x}-\boldsymbol{x}_{\mathrm{a}}\right)+\boldsymbol{\epsilon}+\boldsymbol{b}$

where $\boldsymbol{x}$ represents the true state of an atmospheric variable (ozone profile in this study), while $\boldsymbol{\epsilon}+\boldsymbol{b}$ is the error due to the measurement and retrieval process and can be further separated into the random noise $(\boldsymbol{\epsilon})$ as well as the systematic bias (b). So, the OMI retrieval $\left(\hat{\boldsymbol{x}}^{\mathrm{OMI}}\right)$ and TES retrieval with OMI a priori $\left(\hat{\boldsymbol{x}}^{\mathrm{TES}}\right)$ can be written as:

$\hat{\boldsymbol{x}}^{\mathrm{OMI}}=\boldsymbol{x}_{\mathrm{a}}^{\mathrm{OMI}}+\mathrm{A}^{\mathrm{OMI}}\left(\boldsymbol{x}-\boldsymbol{x}_{\mathrm{a}}^{\mathrm{OMI}}\right)+\boldsymbol{\epsilon}_{\mathrm{OMI}}+\boldsymbol{b}_{\mathrm{OMI}}$

$\hat{\boldsymbol{x}}^{\mathrm{TES}}=\boldsymbol{x}_{\mathrm{a}}^{\mathrm{OMI}}+\mathbf{A}^{\mathrm{TES}}\left(\boldsymbol{x}-\boldsymbol{x}_{\mathrm{a}}^{\mathrm{OMI}}\right)+\boldsymbol{\epsilon}_{\mathrm{TES}}+\boldsymbol{b}_{\mathrm{TES}}$

The difference of directly comparing these two measurements is given by:

$\boldsymbol{\Delta}_{1}=\hat{\boldsymbol{x}}^{\mathrm{OMI}}-\hat{\boldsymbol{x}}^{\mathrm{TES}}=\left(\mathrm{A}^{\mathrm{OMI}}-\mathbf{A}^{\mathrm{TES}}\right)\left(\boldsymbol{x}-\boldsymbol{x}_{\mathrm{a}}^{\mathrm{OMI}}\right)+\boldsymbol{b}_{\mathrm{OMI}}-\boldsymbol{b}_{\mathrm{TES}}$

and the measurement-model differences are:

$\hat{\boldsymbol{x}}^{\mathrm{OMI}}-\hat{\boldsymbol{x}}_{\mathrm{m}}^{\mathrm{OMI}}=\mathbf{A}^{\mathrm{OMI}}\left(\boldsymbol{x}-\boldsymbol{x}_{\mathrm{m}}\right)+\boldsymbol{b}_{\mathrm{OMI}}$

$\hat{\boldsymbol{x}}^{\mathrm{TES}}-\hat{\boldsymbol{x}}_{\mathrm{m}}^{\mathrm{TES}}=\mathbf{A}^{\mathrm{TES}}\left(\boldsymbol{x}-\boldsymbol{x}_{\mathrm{m}}\right)+\boldsymbol{b}_{\mathrm{TES}}$

where $\hat{\boldsymbol{x}}_{\mathrm{m}}^{\mathrm{OMI}}$ and $\hat{\boldsymbol{x}}_{\mathrm{m}}^{\mathrm{TES}}$ are the CTM profiles convolved with the OMI and TES operators, respectively. In Eqs. (6)-(8), the random noise ( $\epsilon_{\mathrm{OMI}}$ and $\left.\epsilon_{\mathrm{TES}}\right)$ is assumed to be zero when averaging over a large area (i.e., $4 \times 5^{\circ}$ box in Zhang et al. (2010) and $5 \times 5^{\circ}$ box here). Note that the measurementmodel differences are independent of the a priori. The difference between Eqs. (7) and (8) gives the OMI-TES difference referring to the CTM:

$$
\begin{aligned}
\boldsymbol{\Delta}_{2} & =\left(\hat{\boldsymbol{x}}^{\mathrm{OMI}}-\hat{\boldsymbol{x}}_{\mathrm{m}}^{\mathrm{OMI}}\right)-\left(\hat{\boldsymbol{x}}^{\mathrm{TES}}-\hat{\boldsymbol{x}}_{\mathrm{m}}^{\mathrm{TES}}\right) \\
& =\left(\mathbf{A}^{\mathrm{OMI}}-\mathbf{A}^{\mathrm{TES}}\right)\left(\boldsymbol{x}-\boldsymbol{x}_{\mathrm{m}}\right)+\boldsymbol{b}_{\mathrm{OMI}}-\boldsymbol{b}_{\mathrm{TES}}
\end{aligned}
$$

Equation (10) is introduced by Zhang et al. (2010) as the "CTM method" to compare two satellite observations, which shows advantages over the direct comparison method (Eq. 6), as the modeled profile is generally closer to the true values than the a priori and consequently adding less noise to the real OMI-TES difference $\boldsymbol{b}_{\text {OMI }}-\boldsymbol{b}_{\text {TES }}$. We note that Zhang et al. (2010) adjusts both OMI and TES retrieval to a fixed a priori, which probably enhances the difference between the original a priori and the true state.

\section{Comparisons in TCO for CTM, OMI and TES}

\subsection{Comparisons of monthly 2-D TCO PDFs for NH middle latitudes and tropics}

The comparisons of TCO between coincident CTM, OMI and TES data are shown as 2-D probability density functions (PDFs) in Fig. 1 for Northern Hemisphere (NH) middle latitudes $\left(25-60^{\circ} \mathrm{N}\right)$ July 2005 (left column) and January 2006 (right column). The number of comparisons $(N)$, mean bias $(\mu)$, standard deviation (STD, $\sigma$ ) of the differences, and coefficient of determination $\left(R^{2}\right)$ are shown for each panel. On panels a and b, the CTM-OMI $R^{2}$ is also calculated for the subsample of TES-OMI coincidence and shown in the parentheses. The mean bias and STD are defined for the verticalaxis variable less the horizontal-axis variable. The correlation coefficient $(R)$ is calculated by removing only the means and without slope correction. There are $\sim 400000$ CTMOMI comparisons each month (Fig. 1a, b), while only $\sim 8000$ CTM-TES pairs (Fig. 1c, d), because of the wide cross-orbit OMI swath and the sparse TES footprint. The high density areas (red and yellow pixels) are generally close to the 1:1 line (black line), reflecting small monthly mean biases between the model and measurements. The largest absolute monthly mean bias ( -4.0 Dobson Unit (DU)) is found between CTM and OMI in July 2005 (Fig. 1a). The CTM is biased low relative to both measurements in July 2005, while it is high in January 2006, pointing to a CTM deficiency. The STDs are at least 1.5 times larger than the mean biases. They are larger in July than in January for both model-measurement comparisons, likely due to larger TCO variations over $\mathrm{NH}$ midlatitudes in summer than in winter, as the variability due to the summer sub-tropical double tropopauses is large and may dominate that due to wintertime variations in the tropopause height. The decrease in the wintertime retrieval sensitivity for OMI caused by the larger solar zenith angle and for TES due to the lower temperature might also contribute to the larger STD in summer than in winter. The model-measurement biases and STDs are similar for both OMI and TES across all months (see Tables S1 and S2 in the Supplement). By contrast, the variations in individual measurements $\left(R^{2}\right)$ are better simulated by the model in July than in January for both OMI and TES. It is not clear why the CTM-OMI correlation is so much higher than that of the CTM-TES on a profile-byprofile basis ( $R^{2}=0.87$ vs. 0.63 in July 2005), since STD is similar in both comparisons and the differences in OMI and TES sampling increase the CTM-OMI $R^{2}$ to 0.90 . In spite 

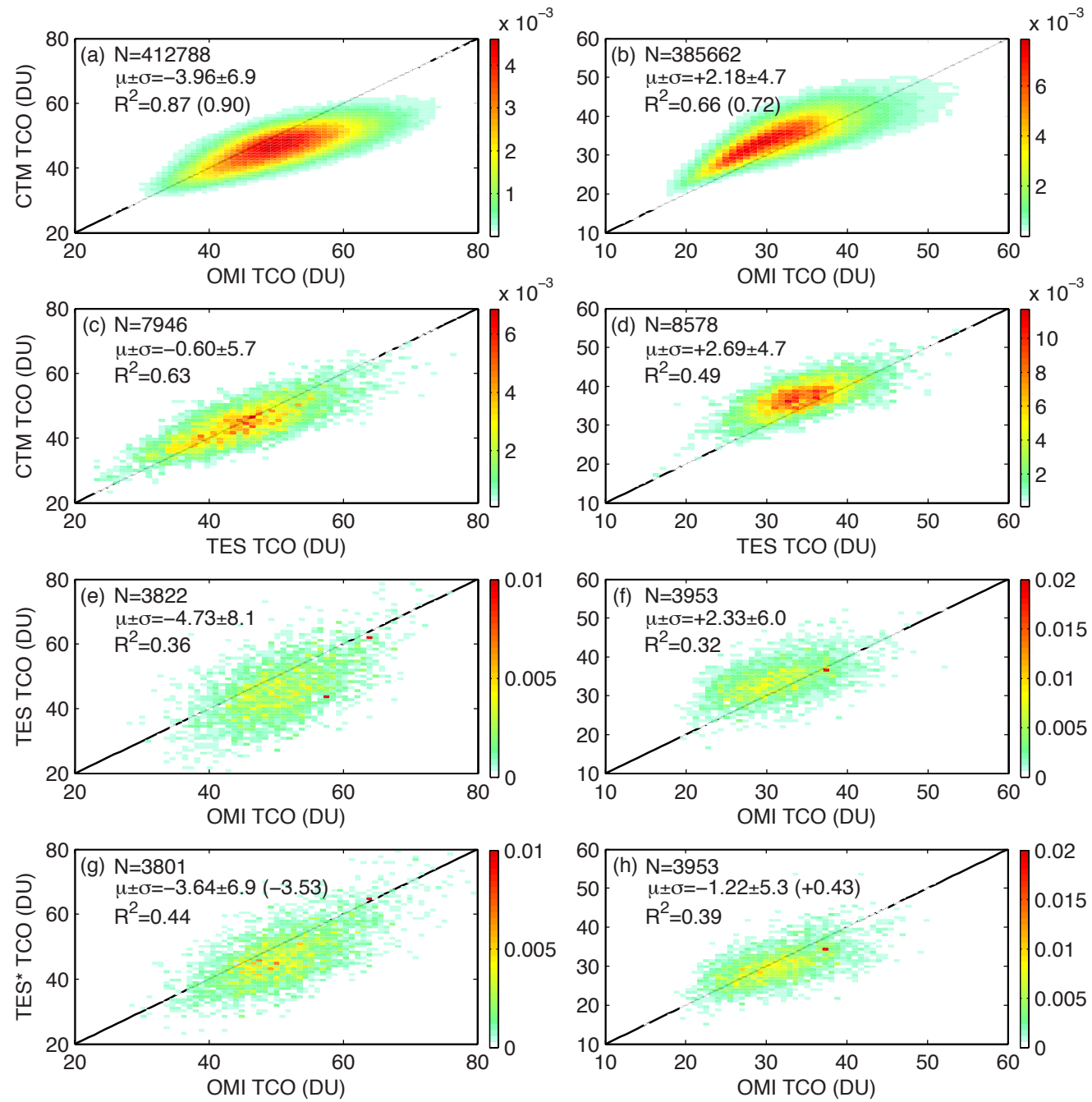

Fig. 1. 2-D TCO PDFs (unit: $\mathrm{DU}^{-2}$ ) of coincident CTM, OMI, and TES data for NH middle latitudes (25-60 N) July 2005 (left column) and January 2006 (right column). Comparisons are shown for each matching pair: (a), (b) CTM vs. OMI; (c), (d) CTM vs. TES; (e), (f) TES vs. OMI; (g), (h) TES ${ }^{\star}$ vs. OMI. TES ${ }^{\star}$ denotes the TES data processed with OMI a priori. The number of comparisons $(N)$, mean bias $(\mu$, unit: DU), standard deviation ( $\sigma$, unit: DU), and coefficient of determination $\left(R^{2}\right)$ are shown for each panel. The mean bias and standard deviation are defined for the vertical-axis variable less the horizontal-axis variable. $R$ is calculated by removing only the means and no slope correction. The values in parentheses on panels (a) and (b) show the CTM-OMI $R^{2}$ subsampled at the TES-OMI coincidence, while on panels $(\mathbf{g})$ and $(\mathbf{h})$ represent the mean TES-OMI biases calculated by the CTM method. The black line represents the 1:1 line.

of having better resolution in the troposphere, the individual TES TCO generally has greater measurement noise (see Tables $\mathrm{S} 1$ and S2 columns 6 and 9).

We selected large regions (e.g., $25-60^{\circ} \mathrm{N}$, all longitudes) because if $5 \times 5^{\circ}$ regions were chosen, the number of CTMTES matches drops to 16 (see later discussion of Fig. 3). Within these large regions, a high $R^{2}$ reflects not only matching the local daily variability, but also the standing latitudeby-longitude patterns in TCO for that month.

Direct comparisons between coincident OMI and TES TCO for July 2005 and January 2006 are shown in Fig. 1e and $\mathrm{f}$. Since OMI measures during the day time, there are only 4000 TES-OMI matching pairs per month. In gen- eral the TES-OMI biases are consistent with the difference between the two model-observation biases within the STD. Overall, this comparison is less satisfactory than either model-observation comparison as the PDFs are more dispersed; the STD larger; and the $R^{2}$ much smaller (see Table S3 for the results of all months). With $R^{2}<0.4$, there is little skill in using one instrument to predict the variance of the other. We conclude that the noise in these two measurements is uncorrelated and the larger TES-OMI STD than model-measurement STD suggests that the noise is larger than the model error.

The differences between TES and OMI TCO are partly attributable to their different retrieval a priori and AK. The 

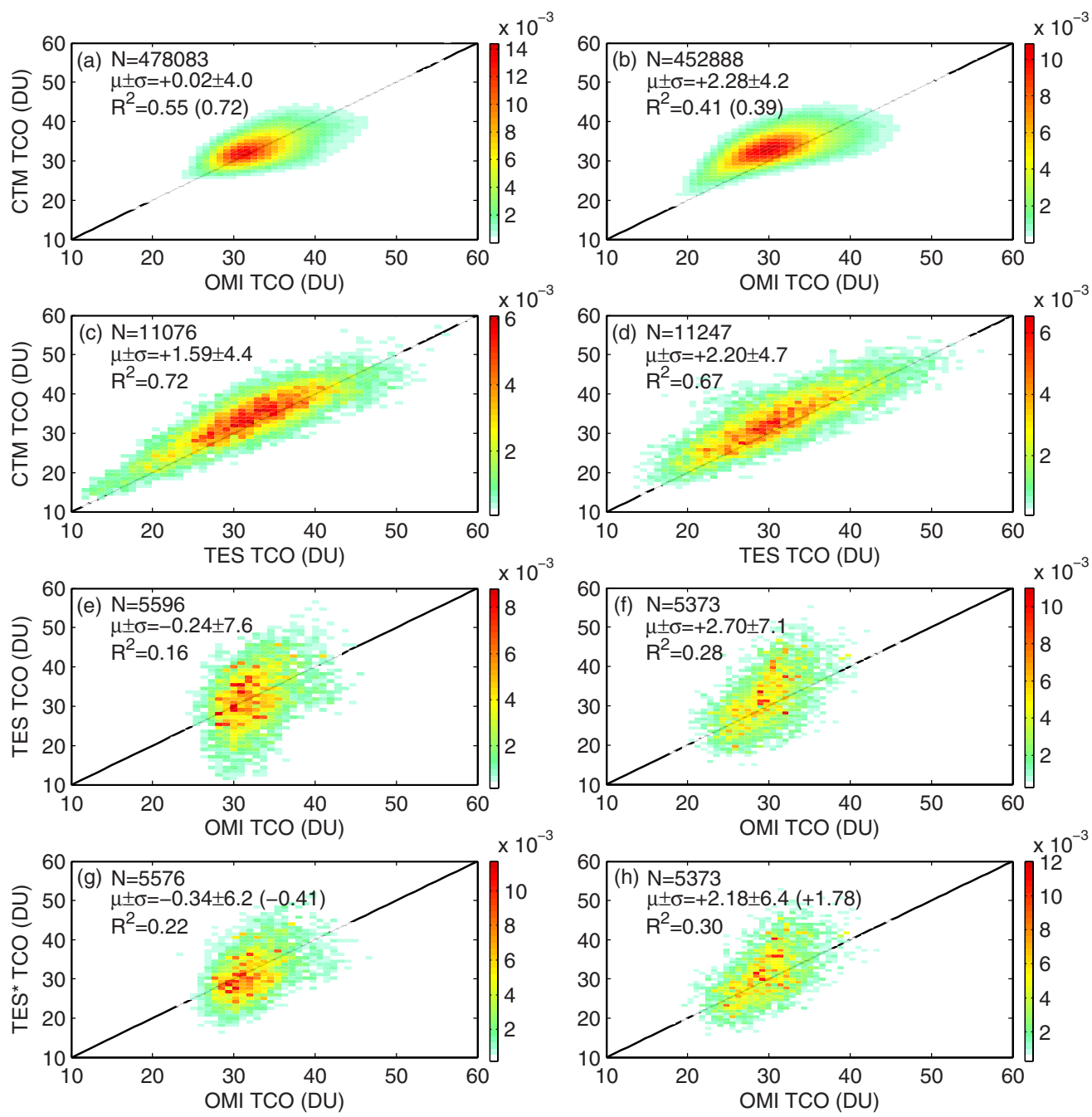

Fig. 2. Same as Fig. 1 for tropics $\left(25^{\circ} \mathrm{S}-25^{\circ} \mathrm{N}\right)$.

influence of different a priori and AK for TCO is expected to be small, since the DOFS in the troposphere are 1-2 for TES (Nassar et al., 2008; Zhang et al., 2010) and about 1 for OMI (de Haan and Veefkind, 2009). To quantify the dependence of TCO on a priori, TES profiles are processed with the OMI a priori by Eq. (2) (denoted by TES ${ }^{\star}$ ) and the results are shown in Fig. $1 \mathrm{~g}$, h. This TES ${ }^{\star}$-OMI comparison is improved compared with the TES-OMI one. The PDF patterns become slightly narrower and denser (Fig. 1g, h vs. Fig. 1e, f), the STD decrease, and the $R^{2}$ increase. Further, the TES ${ }^{\star}$-OMI mean biases $(-3.6$ DU in July 2005 and -1.2 DU in January 2006), calculated by Eq. 6 are now more predictable by the differences between CTM-OMI and CTMTES (-3.4 DU and $-0.5 \mathrm{DU}$, respectively). The values in the parentheses on panels $\mathrm{g}$ and $\mathrm{h}$ show the mean TES-OMI biases referring to the CTM as defined by Eq. 10. The absolute magnitudes of the mean biases become even smaller, as the modeled profile is closer to the reality than the OMI a priori (see Table S4 for the results of all months).
Parallel results for tropics $\left(25^{\circ} \mathrm{S}-25^{\circ} \mathrm{N}\right)$ are illustrated in Fig. 2. The mean CTM TCO bias ranges from 0.0 to $+2.3 \mathrm{DU}$ for both measurements and both months (see Fig. 2a-d). The STD are still much greater than the biases, but are generally smaller than in the NH middle latitudes. The modelmeasurement $R^{2}$ is now better for TES than for OMI. The low TCO $(<20 \mathrm{DU}$, found in Western Pacific) is well matched in CTM-TES, but not CTM-OMI because OMI entirely misses the low TCO. Direct TES-OMI comparisons in the tropics (Fig. 2e, f) show much less correlation than for those in the NH middle latitudes (Fig. 1e, f), except that the absolute bias and STD decrease by $\sim 4.5 \mathrm{DU}$ and $0.5 \mathrm{DU}$ in July 2005. After substituting with the OMI a priori, the TES $^{\star}$-OMI comparisons (Fig. 2g, h) are generally improved, but the low TCO values have disappeared. We conclude that the low tropical TCO reported by TES is probably just the a priori from the MOZART CTM calculations, and thus the apparently better agreement for CTM-TES in the tropics is driven by the close agreement between our CTM and the a 

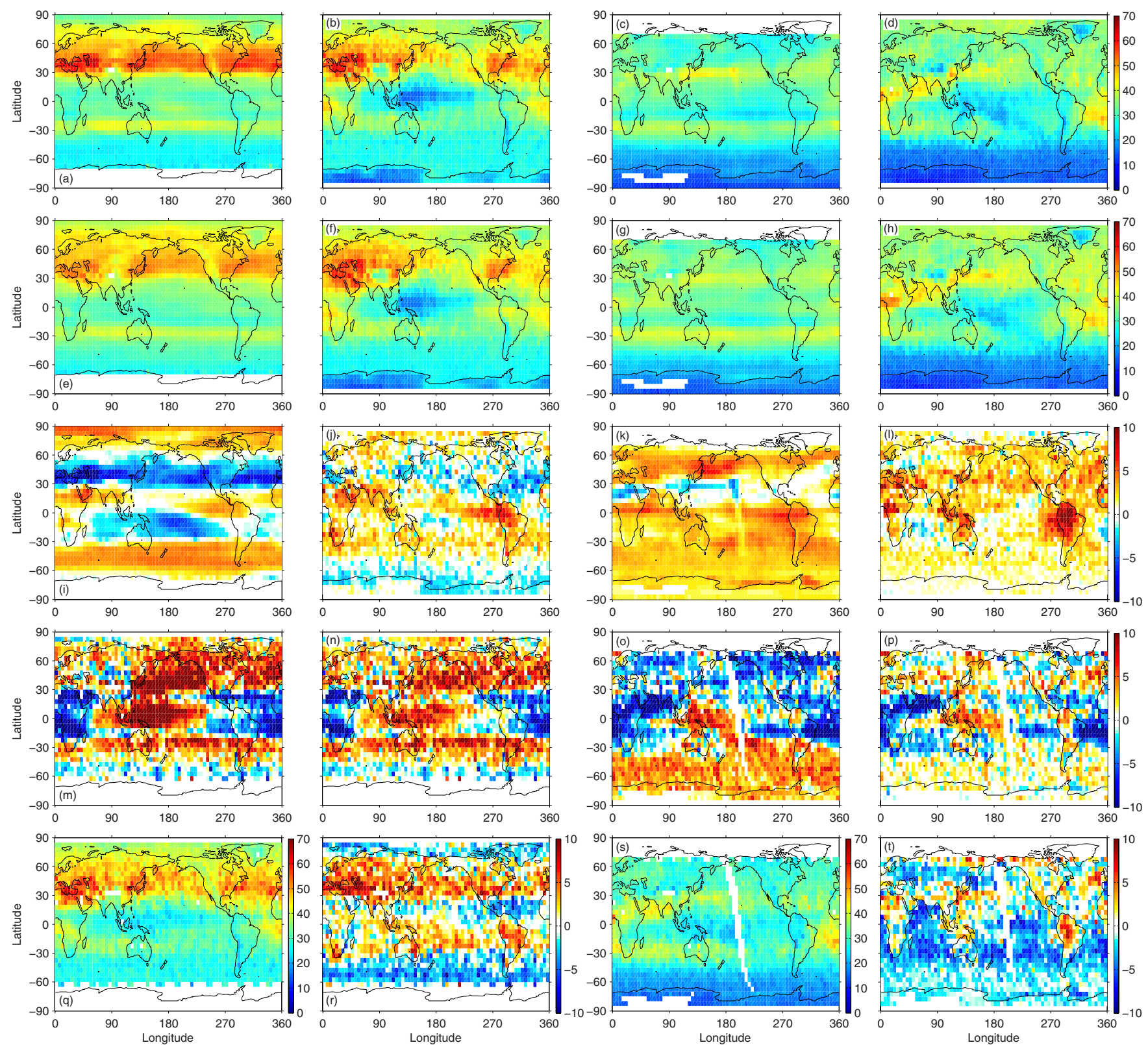

Fig. 3. Latitude-by-longitude comparisons of monthly mean CTM, OMI, and TES TCO (unit: DU) on $5 \times 5^{\circ}$ grid boxes. Results for July 2005 are presented in the first two columns: (a) OMI; (b) TES; (e) CTM coincident with OMI; (f) CTM coincident with TES; (i) CTM-OMI; (j) CTM-TES; (m) OMI-TES; (n) OMI-TES ${ }^{\star} ;$ (q) TES ${ }^{\star} ;$ (r) OMI-TES by the CTM method. All the differences are calculated from exact matching pairs on $5 \times 5^{\circ}$ grids. Parallel results for January 2006 are shown in the third and fourth columns.

priori in terms of tropical TCO patterns. When applying the CTM as a transfer standard, the mean biases in Eq. 10 (shown in parentheses) are generally further reduced. In the tropics, direct TES ${ }^{\star}$-OMI comparisons look more like scatter plots $\left(R^{2}<0.3\right)$; whereas the model-observation comparisons indicate some skill in prediction $\left(R^{2}=0.4 \sim 0.7\right)$, only part of which can be due to the a priori. Other contributing factors are differences in AKs and uncorrelated measurement noise.

\subsection{Comparisons of monthly mean TCO latitude-by-longitude patterns}

Figure 3 shows the comparisons in monthly mean TCO among CTM, OMI and TES as a function of latitude and longitude on $5 \times 5^{\circ}$ grids for July 2005 (first and second columns) and January 2006 (third and fourth columns). The reported OMI AK contains unreasonable values where the surface pressure is less than $700 \mathrm{hPa}$, and we drop those data, causing white spaces at Tibet and Antarctic Plateau. 
The OMI TCO field (Fig. 3a) is much smoother compared to that of TES (Fig. 3b) in part because of the 800 vs. 16 points per grid cell. The uniformly high OMI TCO bands at $\mathrm{NH}$ middle latitudes and $30^{\circ} \mathrm{S}$ (noted in Tang and Prather, 2010) are unrealistic and largely attributable to latitudinal jumps in the OMI a priori profiles. Low Pacific TCO values $(<20 \mathrm{DU})$ and high Atlantic values ( $>40 \mathrm{DU})$ (i.e., wave-1 pattern) over the equatorial regions, seen in previous observations (e.g., Davis et al., 1996; Crawford et al., 1997; Browell et al., 2003; Thompson et al., 2003), are modeled in most CTMs, and are reported by TES but not OMI, nor by the UCI CTM processed with the OMI operator (Fig. 3e). The high ozone over South Atlantic is found extending from the lower troposphere through the upper troposphere in the SHADOZ ozonesonde (Thompson et al., 2003) and is a consequence of the combination of many processes, such as biomass burning, lightning, Walker circulation and cross equator transport (e.g., Fishman and Larsen, 1987; Martin et al., 2002; Edwards et al., 2003). Although OMI has some sensitivity down to the surface, the inability to report such low TCO over the equatorial Pacific and high ozone over the South Atlantic likely results from the retrieval fitting algorithm of this OMI ozone profile product (OMO3PR V003), as another retrieval algorithm with the same monthly zonal mean climatological a priori (McPeters et al., 2007) can capture such wave-1 pattern in the TCO (Liu et al., 2010, Fig. 8c). The CTM means are averaged from coincident simulations for OMI (Fig. 3e) and TES (Fig. 3f). The patterns of corresponding pairs are quite similar, but the modeled TCO show consistent directions of biases relative to both measurements for many regions (see Fig. 3i, j for CTM-OMI and CTM-TES differences), such as underestimations at $\mathrm{NH}$ middle latitudes and Southern Hemisphere equatorial Pacific Ocean and overestimations at Africa, Southern Asia, and equatorial Pacific Ocean and South America. These model-measurement biases are consistent across both OMI and TES and suggest model deficiencies in these regions, but may also be a consequence of common features of OMI and TES, such as low sensitivities in the lower troposphere, causing these measurements to miss high $\mathrm{O}_{3}$ from biomass burning emerging out of South America and Africa. In the biomass burning regions (e.g., South America and Western Africa), the CTM reports closer TCO values to those of Ziemke et al. (2009) than OMI and TES in these months. On the other hand, Zhang et al. (2010) finds that OMI and TES can detect enhanced ozone due to biomass burning at $500 \mathrm{hPa}$. Therefore, further analysis and measurements (e.g., SHADOZ ozonesonde) are required to determine which TCO is closer to the reality.

The zonally averaged OMI-TES biases are small $(|\mu|<$ 5 DU see Figs. 1 and 2), but hide the larger, systematic OMI-TES differences at the continental scale that can exceed \pm 10 DU, over Africa, Pacific Ocean, and tropical Atlantic Ocean (Fig. $3 \mathrm{~m}$ ). These differences are partly due to different a priori profiles used in the two retrievals. Figure $3 q$ shows the TES TCO after adjusting with OMI a priori. When using the same a priori (Fig. 3n), the OMI-TES differences are generally reduced by a few DU but show the same large regional biases. The dependence of retrieved TCO on the a priori profile varies spatially, for instance, the OMI-TES comparisons are greatly improved over North and Central Pacific, but remain almost the same at $30^{\circ} \mathrm{S}$ and South Atlantic. The differences that cannot be explained by a priori are shown in Eq. (6) as the true OMI-TES differences $\boldsymbol{b}_{\mathrm{OMI}}-\boldsymbol{b}_{\mathrm{TES}}$ plus the term $\left(\mathbf{A}^{\mathrm{OMI}}-\mathbf{A}^{\mathrm{TES}}\right)\left(\boldsymbol{x}-\boldsymbol{x}_{\mathrm{a}}^{\mathrm{OMI}}\right)$ that reflects the differences between the OMI a priori and the true ozone profile smoothed by OMI-TES AK differences.

Figure 3r illustrates the OMI-TES differences referring to the CTM calculated by Eq. 10. Comparing Fig. 3n vs. r, the differences are generally reduced (denoted with lighter colors in panel $r$ ) when applying the CTM as the transfer standard. The main advantage of Eq. (10) over Eq. (6) is that it partly removes the noise due to different AKs by matching the true ozone profile with the CTM simulation that is more realistic than the retrieval a priori. Therefore, the difference is reduced more over the tropics where the AK differences are larger (see Zhang et al., 2010, Fig. 2 for the tropospheric AK patterns). The tropical wave-1 pattern in Fig. $3 \mathrm{n}$ disappears in Fig. 3r, suggesting that this pattern is primarily caused by the first, noise term on the right side of Eq. (6). Nevertheless, the differences increase over places, for instance Middle East. Considering that the differences generally become smaller in the NH middle latitudes and no systematic bias is found for the model in the Middle East, this large ( $~ 10$ DU) OMI-TES bias spot is likely real and it is masked by the noise in the direct comparison. It is not clear why the difference has opposite sign but with similar magnitudes over South America. We note that the CTM method brings into the comparison the model error and hence it is important to take into account the model deficiencies when interpreting the results.

Parallel results for January 2006 are shown in the third and fourth columns of Fig. 3. Compared to July 2005, the CTM is still biased high in both cases over South America, but biased in the opposite direction for most $\mathrm{NH}$ middle latitudes, indicating a possible pattern of model error. As to the OMI-TES differences, the negative-positive-negative longitudinal pattern in the tropics occurs for both July 2005 and January 2006 for the direct comparison but not for the CTM method. On the other hand, the OMI-TES differences change sign for $\mathrm{NH}$ middle latitudes and $\mathrm{SH}$ middle-high latitudes (see Fig. $3 \mathrm{~m}$ and o), reflecting the seasonality of a priori information. Removing the influence from different a priori (see Fig. 3o and p), differences are greatly reduced in extratropics of both hemispheres, while discrepancies remain in the tropics, which is generally reduced with the CTM method (see Fig. 3p and t). 
Table 1. Monthly zonal mean TCO (unit: DU) from TES separated by day and night and compared with coincident CTM simulations*.

\begin{tabular}{|c|c|c|c|c|c|c|c|c|}
\hline \multirow[b]{3}{*}{ Regions } & \multicolumn{4}{|c|}{ July 2005} & \multicolumn{4}{|c|}{ January 2006} \\
\hline & & Day & & Night & & Day & & Night \\
\hline & TES & CTM-TES & TES & CTM-TES & TES & CTM-TES & TES & CTM-TES \\
\hline NH mid & 47.0 & $-0.7 \pm 5.9$ & 42.9 & $-0.3 \pm 5.2$ & 34.6 & $+2.6 \pm 4.5$ & 32.5 & $+3.0 \pm 4.7$ \\
\hline Tropics & 32.6 & $+1.8 \pm 4.4$ & 32.7 & $+1.4 \pm 4.2$ & 32.6 & $+2.4 \pm 4.6$ & 30.6 & $+2.7 \pm 4.8$ \\
\hline SH mid & 28.5 & $+1.1 \pm 4.2$ & 27.8 & $+1.0 \pm 4.2$ & 24.6 & $+1.2 \pm 3.5$ & 24.8 & $+1.3 \pm 3.3$ \\
\hline
\end{tabular}

${ }^{*}$ Latitude ranges are $\mathrm{NH}$ mid $\left(25-60^{\circ} \mathrm{N}\right)$, tropics $\left(25^{\circ} \mathrm{S}-25^{\circ} \mathrm{N}\right)$, SH mid $\left(60-25^{\circ} \mathrm{S}\right)$. See Figs. 1 and 2 for number of points in the sample, about $4-5 \times 10^{3}$ for both day and night in each region. Single numbers are the TES monthly means, while the remaining shows bias \pm STD.

Table 2. Same as Table 1 for TES a priori.

\begin{tabular}{l|cc|cc|cc|cc}
\hline & \multicolumn{4}{|c|}{ July 2005 } & \multicolumn{3}{c}{ January 2006 } \\
\cline { 2 - 8 } & \multicolumn{3}{|c|}{ Day } & \multicolumn{2}{c|}{ Night } & & Day & Night \\
\cline { 2 - 9 } Regions & TES & CTM-TES & TES & CTM-TES & TES & CTM-TES & TES & CTM-TES \\
\hline NH mid & 54.7 & $-8.3 \pm 13.3$ & 51.4 & $-8.8 \pm 14.1$ & 40.1 & $-3.0 \pm 7.9$ & 38.2 & $-2.7 \pm 7.5$ \\
Tropics & 31.4 & $+3.0 \pm 8.4$ & 32.3 & $+1.8 \pm 7.8$ & 35.6 & $-0.5 \pm 5.9$ & 33.5 & $-0.2 \pm 5.6$ \\
SH mid & 29.0 & $+0.6 \pm 5.9$ & 28.6 & $+0.2 \pm 5.6$ & 27.6 & $-1.8 \pm 6.2$ & 28.1 & $-1.9 \pm 6.3$ \\
\hline
\end{tabular}

\section{Day-night differences in TES}

TES provides both day and night observations of tropospheric $\mathrm{O}_{3}$ for each orbit. We do not expect, nor model, a significant diurnal cycle in TCO. Nevertheless, there is a possibility that day-night TES observations differ systematically because of the interference of scattered sunlight in the instrument or because of the different ambient conditions on the spacecraft such as temperature on the sunlit part of the orbit. Individual TES level 2 profiles can be separated by day vs. night and averaged into a gridded, monthly mean level 3 product, but different sampling times (e.g., relative to a TF) and low sampling densities (e.g., 8 profiles per $5 \times 5^{\circ}$ daytime grid cell) can produce spurious day-night differences that are much larger than the true day-night bias. Using the CTM as a transfer standard between day and night observations provides a unique capability for removing this sampling error and quantifying the day-night bias to a better precision. The day-night comparison on small gridded regions (not shown) proved very noisy because of the limited number of monthly TES observations. Thus in Table 1 we examine the day-night biases and standard deviation in TCO (DU) for CTM minus TES using monthly zonally averaged regions, each containing about $4-5 \times 10^{3}$ TES observations each for day and night. We use the OMI tracks as masks to separate TES profiles into day (with OMI data) vs. night (without OMI data).

TES data have large day-night differences in some locations and some months, but these are predicted by the CTM and are due to sampling bias. For example, at NH mid-latitudes in July 2005, the daytime TCO, 47 DU, drops to $43 \mathrm{DU}$ for night. The CTM-TES bias remains essentially unchanged $(-0.7$ to $-0.3 \mathrm{DU})$ indicating that the $4 \mathrm{DU}$ drop is predicted. The $\mathrm{NH}$ mid-latitude day-night difference is +2 DU in January 2006 and is also mostly predicted by the CTM. In the tropics there is no day-night difference in July 2005, but a +2 DU in January 2006. SH mid-latitudes have no day-night difference in both months, probably due to the zonal symmetry of the jet and pollution sources. Using the model, whose bias relative to TES does not change from day to night, we can confidently predict that an systematic daynight bias in TES TCO is less than 0.4 DU (1\%) for the cases here. Part of the predictability of the day-night differences here involves different latitudinal sampling of day and night near $60^{\circ}$ latitude at the solstices, but the tropical differences in January 2006 are not an obvious sampling issues. Without the CTM as a transfer, some day-night differences approach $10 \%$ and it would be difficult to reduce this by going to smaller regions with fewer observations. Another positive feature here is that the standard deviation of the CTM minus TES differences remains virtually unchanged between day and night. We conclude that the noise in individual TCO retrievals is unchanged from day to night. While the noise level of individual TES TCO is modest $(\sim 10 \%)$ and not unexpected, the stability of the instrument and the day-night biases are remarkable $(\sim 1 \%)$.

It is possible that the consistency in the TES daynight TCO only reflects a priori information based on the MOZART CTM and would thus be free of day-night bias. Table 2 shows the parallel statistics for the TES a priori day-night TCO using the same sampling as in Table 1 . The 
corrections that TES retrieval adds to its a priori (i.e., Table 1 minus Table 2) vary with locations and months and represent the TES measurement signals. Despite the great reductions in the TCO monthly means (up to $8 \mathrm{DU}$ ) and in the STD of CTM minus TES a priori (up to 9DU), the differences in the day-night CTM-TES bias between TES a priori and TES TCO remain essentially the same $( \pm 0.1 \mathrm{DU})$ or become smaller (from 1.2 DU to 0.4 DU in the tropics in July 2005). In other words, TES measurement signals do not have daynight bias and can even improve the day-night consistency in our sampling of the TES a priori.

\section{Discussion and conclusions}

In this paper we present a detailed analysis of the NASA Aura level 2 (L2) tropospheric column ozone (TCO) data from OMI and TES. We compare coincident pairs of OMI, TES, and CTM simulations for years 2005-2006 that are time-matched and geo-collocated OMI on the CTM grid, using all recommended observations between $60^{\circ} \mathrm{S}$ and $60^{\circ} \mathrm{N}$ from OMI ( 30000 000) and TES ( 65000$)$. There is generally good agreement in the TCO between the satellite observations and the model as well as between OMI and TES and hence these two datasets can be used to define a TCO climatology with recognition of the weakness in detecting lower tropospheric ozone. Since the OMI product (OMO3PR V003) encounters problems, such as lack of tropical wave1 pattern and uniform middle latitude TCO bands, another OMI product free of these issues (Liu et al., 2010) is probably a better choice for deriving TCO climatologies. As to the monthly zonal means over different latitude bands, either CTM-OMI or CTM-TES biases are less than 6DU (20\%) but usually smaller. A consistent bias identified in the CTM relative to both observations suggests model errors, for example, the CTM is low in July 2005, but high in January 2006 at NH mid-latitudes. Direct comparisons of coincident OMITES TCO observations avoids these model uncertainties, yet it yields higher standard deviations due to the inclusion of both OMI and TES profile noise as well as the difference between the true state and the OMI a priori as smoothed by the OMI-TES AK difference. We conclude that the single-profile noise in these two TCO measurements is largely uncorrelated and is very likely to be larger than the model uncertainties. Thus, there is better predictability between the almost noisefree model and the measurement than between the two measurements. This level of noise, typically 2-4DU for small $5 \times 5^{\circ}$ regions (see Tables S4, S8, S12, S16, S20, S24 for OMI-TES $^{\star}$ STD) makes it difficult to match single measurements involving tropopause folds or stratospheric intrusions of high- $\mathrm{O}_{3}$ air. In some cases the event is large enough, or sampled multiply (as in the OMI swath data) that it can be detected (Pan et al., 2009). Indeed, we also find regions where a large fraction of the variability in OMI TCO, presumably due to TFs, is matched by the CTM (Tang and Prather, 2010).
A common feature of the three comparisons here is that the standard deviations (STD) of the differences (or equivalently the root mean square errors) are much larger than the mean biases for large zonal regions in most months (see Tables S1S24), and thus there must be some type of noise in the individual coincident comparisons. This feature is consistent with the OMI and TES validation against ozone sondes (e.g., Nassar et al., 2008; Osterman et al., 2008; Zhang et al., 2010; Kroon et al., 2011). However, there are several exceptions, for example at SH mid-latitudes the CTM-OMI comparisons in May-December 2006 (Table S21) and CTM-TES comparison in November 2006 (Table S22). In these cases the relatively larger mean biases of model-measurement comparisons clearly identify model deficiencies, as for most months the OMI and TES TCO are consistent in terms of the much smaller mean biases than STD of OMI minus TES ${ }^{\star}$ (Table S24).

Comparison of exactly overlapping OMI and TES measurements shows great advantages for cross-validation. Kroon et al. (2011) validated the OMI and TES ozone profiles for cloud-free scenes. We chose not to exclude the cloudy pixels to retain enough comparisons on $5 \times 5^{\circ}$ grids. In spite of the fact that a priori information dominates the ozone profiles below clouds, especially for the infrared sounder TES, the monthly mean OMI-TES ${ }^{\star}$ biases in TCO identified in this study are in good agreement with the persistent tropospheric structures illustrated by Kroon et al. (2011), which highlights the importance of correcting the a priori differences when comparing different satellite datasets. Although the tropospheric AKs for both measurements are relatively small compared to those in the stratosphere, the difference in the AK still causes large noise when gridded at $5 \times 5^{\circ}$. When using the CTM, the OMI-TES differences are generally reduced because of the lessened impact from AK difference via matching true ozone profile with the model simulation instead of the OMI a priori. Our results are consistent with Zhang et al. (2010), which shows that the CTM method is better than the direct comparison for quantifying the differences between different satellite measurements. We note that the CTM method (Eq. 10) can only be applied for the bias calculation, and is not applicable for the STD and correlations. We also note that the advantage of the CTM method over the direct comparison is more obvious where the $\mathrm{AK}$ difference is larger and the model error may lead to artificial differences.

A high bias of about +4 DU for TES TCO has been shown from the validation with sondes for large regions (Osterman et al., 2008), while no equivalent validation for the OMI TCO product is yet available. Our results show that the zonal mean OMI and TES TCO agree within 5-10\% and imply that the zonal mean OMI TCO bias is at most a few Dobson Units. The bias calculated by the CTM method is smaller than direct comparison for most months, but the ranges are similar for both (see Tables S4, S8, S12, S16, S20, S24 column 3). A bias of $+4 \mathrm{DU}$ is at the upper limit (depending on location) of 
those which might be inferred from the three-way comparison or the CTM method here of many times more profiles than possible with sonde comparisons. Nevertheless, when restricting the comparisons over smaller regions (i.e., $5 \times 5^{\circ}$ grids), even with corrections for a priori the local OMI-TES differences are greater than $\pm 10 \mathrm{DU}$ at many areas, for example tropics. These large local differences reflect different sensitivities (i.e., averaging kernels) of the two instruments/algorithms at different locations. Applying the CTM as the transfer standard decreases much of the OMI-TES differences in the tropics, but increases at many regions, for example Middle East in July 2005 and South America in July 2005 and January 2006. These large local differences could be real, but only if the model error in these regions can be excluded.

Our unique approach to quantifying the possible day-night differences in the TES observations using all L2 data and coincident CTM profiles has demonstrated no biases and no change in individual measurement noise. This double result is reassuring given that there are much larger latitudinal, seasonal, and even day-night differences, but these are generally predicted by the CTM.

\section{Supplementary material related to this article is available online at: http://www.atmos-chem-phys.net/12/ 10441/2012/acp-12-10441-2012-supplement.pdf.}

Acknowledgements. We thank the Aura science team, particularly the OMI and TES researchers, for insight and assistance in this analysis. This research was supported by NASA's atmospheric chemistry and modeling, analysis, and prediction programs (grants NNG06GB84G and NNX09AJ47G to UCI) and NSF grant (AGS-1042787 to Cornell University).

Edited by: R. Harley

\section{References}

Brasseur, G. P., Hauglustaine, D. A., Walters, S., Rasch, R. J., Müller, J., Granier, C., and Tie, X. X.: MOZART, a global chemical transport model for ozone and related chemical tracers 1. Model description, J. Geophys. Res., 103, 28265-28289, doi:10.1029/98JD02397, 1998.

Browell, E. V., Fenn, M. A., Butler, C. F., Grant, W. B., Brackett, V. G., Hair, J. W., Avery, M. A., Newell, R. E., Hu, Y., Fuelberg, H. E., Jacob, D. J., Anderson, B. E., Atlas, E. L., Blake, D. R., Brune, W. H., Dibb, J. E., Fried, A., Heikes, B. G., Sachse, G. W., Sandholm, S. T., Singh, H. B., Talbot, R. W., Vay, S. A., Weber, R. J., and Bartlett, K. B.: Large-scale ozone and aerosol distributions, air mass characteristics, and ozone fluxes over the western Pacific Ocean in late winter/early spring, J. Geophys. Res., 108, 8805, doi:10.1029/2002JD003290, 2003.
Carver, G., Brown, P., and Wild, O.: The ASAD atmospheric chemistry integration package and chemical reaction database, Comput. Phys. Commun., 105, 197-215, 1997.

Crawford, J., Davis, D., Chen, G., Bradshaw, J., Sandholm, S., Kondo, Y., Liu, S., Browell, E., Gregory, G., Anderson, B., Sachse, G., Collins, J., Barrick, J., Blake, D., Talbot, R., and Singh, H.: An assessment of ozone photochemistry in the extratropical western North Pacific: Impact of continental outflow during the late winter/early spring, J. Geophys. Res., 102, 28469 28487, 1997.

Davis, D. D., Crawford, J., Chen, G., Chameides, W., Liu, S., Bradshaw, J., Sandholm, S., Sachse, G., Gregory, G., Anderson, B., Barrick, J., Bachmeier, A., Collins, J., Browell, E., Blake, D., Rowland, S., Kondo, Y., Singh, H., Talbot, R., Heikes, B., Merrill, J., Rodriguez, J., and Newell, R. E.: Assessment of ozone photochemistry in the western North Pacific as inferred from PEM-West A observations during the fall 1991, J. Geophys. Res., 101, 2111-2134, 1996.

de Haan, J. F. and Veefkind, J. P.: OMO3PR Readme, http://disc.sci.gsfc.nasa.gov/Aura/data-holdings/OMI/ documents/v003/OMO3PRO_README.html, access: 18 June 2012, 2009.

Edwards, D. P., Lamarque, J.-F., Attié, J.-L., Emmons, L. K., Richter, A., Cammas, J.-P., Gille, J. C., Francis, G. L., Deeter, M. N., Warner, J., Ziskin, D. C., Lyjak, L. V., Drummond, J. R., and Burrows, J. P.: Tropospheric ozone over the tropical Atlantic: A satellite perspective, J. Geophys. Res., 108, 4237, doi:10.1029/2002JD002927, 2003

Eyring, V., Shepherd, T. G., and Waugh, D. W., eds.: SPARC Report on the Evaluation of Chemistry-Climate Models, SPARC Report No. 5, WCRP-132, WMO/TD-No. 1526, http://www. sparc-climate.org/, 2010

Fishman, J. and Larsen, J. C.: Distribution of total ozone and stratospheric ozone in the tropics: Implications for the distribution of tropospheric ozone, J. Geophys. Res., 92, 6627-6634, doi:10.1029/JD092iD06p06627, 1987.

Ho, S., Edwards, D. P., Gille, J. C., Luo, M., Osterman, G. B., Kulawik, S. S., and Worden, H.: A global comparison of carbon monoxide profiles and column amounts from Tropospheric Emission Spectrometer (TES) and Measurements of Pollution in the Troposphere (MOPITT), J. Geophys. Res., 114, D21307, doi:10.1029/2009JD012242, 2009.

Holmes, C. D., Tang, Q., and Prather, M. J.: Uncertainties in climate assessment for the case of aviation NO, P. Natl. Acad. Sci. USA, 108, 10997-11002, doi:10.1073/pnas.1101458108, 2011.

Hsu, J. and Prather, M. J.: Stratospheric variability and tropospheric ozone, J. Geophys. Res., 114, D06102, doi:10.1029/2008JD010942, 2009.

Isaksen, I. S. A., Zerefos, C., Kourtidis, K., Meleti, C., Dalsoren, S. B., Sundet, J. K., Grini, A., Zanis, P., and Balis, D.: Tropospheric ozone changes at unpolluted and semipolluted regions induced by stratospheric ozone changes, J. Geophys. Res., 110, D02302, doi:10.1029/2004JD004618, 2005.

Kraabøl, A. G., Berntsen, T. K., Sundet, J. K., and Stordal, F.: Impacts of $\mathrm{NO}_{x}$ emissions from subsonic aircraft in a global three-dimensional chemistry transport model including plume processes, J. Geophys. Res., 107, 4655, doi:10.1029/2001JD001019, 2002. 
Kroon, M., de Haan, J. F., Veefkind, J. P., Froidevaux, L., Wang, R., Kivi, R., and Hakkarainen, J. J.: Validation of operational ozone profiles from the Ozone Monitoring Instrument, J. Geophys. Res., 116, D18305, doi:10.1029/2010JD015100, 2011.

Levelt, P. F., Hilsenrath, E., Leppelmeier, G. W., van den Oord, G. H. J., Bhartia, P. K., Tamminen, J., de Haan, J. F., and Veefkind, J. P.: Science Objectives of the Ozone Monitoring Instrument, IEEE Trans. Geosci. Remote Sens., 44, 1199-1208, doi:10.1109/TGRS.2006.872336, 2006.

Liu, X., Bhartia, P. K., Chance, K., Spurr, R. J. D., and Kurosu, T. P.: Ozone profile retrievals from the Ozone Monitoring Instrument, Atmos. Chem. Phys., 10, 2521-2537, doi:10.5194/acp-10-25212010, 2010.

Luo, M., Rinsland, C., Fisher, B., Sachse, G., Diskin, G., Logan, J., Worden, H., Kulawik, S., Osterman, G., Eldering, A., Herman, R., and Shephard, M.: TES carbon monoxide validation with DACOM aircraft measurements during INTEX-B 2006, J. Geophys. Res., 112, D24S48, doi:10.1029/2007JD008803, 2007a.

Luo, M., Rinsland, C. P., Rodgers, C. D., Logan, J. A., Worden, H., Kulawik, S., Eldering, A., Goldman, A., Shephard, M. W., Gunson, M., and Lampel, M.: Comparison of carbon monoxide measurements by TES and MOPITT: Influence of a priori data and instrument characteristics on nadir atmospheric species retrievals, J. Geophys. Res., 112, D09303, doi:10.1029/2006JD007663, $2007 b$.

Martin, R. V., Jacob, D. J., Logan, J. A., Bey, I., Yantosca, R. M., Staudt, A. C., Li, Q., Fiore, A. M., Duncan, B. N., Liu, H., Ginoux, P., and Thouret, V.: Interpretation of TOMS observations of tropical tropospheric ozone with a global model and in situ observations, J. Geophys. Res., 107, 4351, doi:10.1029/2001JD001480, 2002.

McPeters, R. D., Labow, G. J., and Logan, J. A.: Ozone climatological profiles for satellite retrieval algorithms, J. Geophys. Res., 112, D05308, doi:10.1029/2005JD006823, 2007.

Nassar, R., Logan, J. A., Worden, H. M., Megretskaia, I. A., Bowman, K. W., Osterman, G. B., Thompson, A. M., Tarasick, D. W., Austin, S., Claude, H., Dubey, M. K., Hocking, W. K., Johnson, B. J., Joseph, E., Merrill, J., Morris, G. A., Newchurch, M., Oltmans, S. J., Posny, F., Schmidlin, F. J., Vömel, H., Whiteman, D. N., and Witte, J. C.: Validation of Tropospheric Emission Spectrometer (TES) nadir ozone profiles using ozonesonde measurements, J. Geophys. Res., 113, D15S17, doi:10.1029/2007JD008819, 2008.

OMI Team: Ozone Monitoring Instrument (OMI) Data User's Guide, OMI-DUG-3.0, http://disc.sci.gsfc.nasa.gov/Aura/ additional/documentation/README.OMI_DUG.pdf, access: 4 August 2010, 2009.

Osterman, G., Bowman, K., Eldering, A., Fisher, B., Herman, R., Jacob, D., Jourdain, L., Kulawik, S., Luo, M., Monarrez, R., Paradise, S., Payne, V., Poosti, S., Richards, N., Rider, D., Shepard, D., Shephard, M., Vilnrotter, F., Worden, H., Worden, J., Yun, H., and Zhang, L.: Earth Observing System (EOS) Tropospheric Emission Spectrometer (TES) Level 2 (L2) Data User's Guide (Up to \& including Version 4 data), Tech. Rep. D-38042, Version 4.0, JPL, Jet Propulsion Laboratory California Institute of Technology Pasadena, California, USA, 91109-8099, 2009.

Osterman, G. B., Kulawik, S. S., Worden, H. M., Richards, N. A. D., Fisher, B. M., Eldering, A., Shephard, M. W., Froidevaux, L., Labow, G., Luo, M., Herman, R. L., Bowman, K. W., and
Thompson, A. M.: Validation of Tropospheric Emission Spectrometer (TES) measurements of the total, stratospheric, and tropospheric column abundance of ozone, J. Geophys. Res., 113, D15S16, doi:10.1029/2007JD008801, 2008.

Pan, L. L., Randel, W. J., Gille, J. C., Hall, W. D., Nardi, B., Massie, S., Yudin, V., Khosravi, R., Konopka, P., and Tarasick, D.: Tropospheric intrusions associated with the secondary tropopause, J. Geophys. Res., 114, D10302, doi:10.1029/2008JD011374, 2009.

Park, M., Randel, W. J., Kinnison, D. E., Garcia, R. R., and Choi, W.: Seasonal variation of methane, water vapor, and nitrogen oxides near the tropopause: Satellite observations and model simulations, J. Geophys. Res., 109, D03302, doi:10.1029/2003JD003706, 2004.

Prather, M. J. and Hsu, J.: Coupling of Nitrous Oxide and Methane by Global Atmospheric Chemistry, Science, 330, 952-954, doi:10.1126/science.1196285, 2010.

Prather, M. J., Zhu, X., Strahan, S. E., Steenrod, S. D., and Rodriguez, J. M.: Quantifying errors in trace species transport modeling, P. Natl. Acad. Sci. USA, 105, 19617-19621, doi:10.1073/pnas.0806541106, 2008.

Prather, M. J., Zhu, X., Tang, Q., Hsu, J., and Neu, J. L.: An atmospheric chemist in search of the tropopause, J. Geophys. Res., 116, D04306, doi:10.1029/2010JD014939, 2011.

Rodgers, C. D. and Connor, B. J.: Intercomparison of remote sounding instruments, J. Geophys. Res., 108, 4116, doi:10.1029/2002JD002299, 2003.

Schoeberl, M. R., Douglass, A. R., Hilsenrath, E., Bhartia, P. K., Beer, R., Waters, J. W., Gunson, M. R., Froidevaux, L., Gille, J. C., Barnett, J. J., Levelt, P. F., and DeCola, P.: Overview of the EOS Aura Mission, IEEE Trans. Geosci. Remote Sens., 44, 1066-1074, doi:10.1109/TGRS.2005.861950, 2006.

Tang, Q. and Prather, M. J.: Correlating tropospheric column ozone with tropopause folds: the Aura-OMI satellite data, Atmos. Chem. Phys., 10, 9681-9688, doi:10.5194/acp-10-9681-2010, 2010.

Tang, Q. and Prather, M. J.: Five blind men and the elephant: what can the NASA Aura ozone measurements tell us about stratosphere-troposphere exchange?, Atmos. Chem. Phys., 12, 2357-2380, doi:10.5194/acp-12-2357-2012, 2012.

Tang, Q., Prather, M. J., and Hsu, J.: Stratosphere-troposphere exchange ozone flux related to deep convection, Geophys. Res. Lett., 38, L03806, doi:10.1029/2010GL046039, 2011.

Thompson, A. M., Witte, J. C., Oltmans, S. J., Schmidlin, F. J., Logan, J. A., Fujiwara, M., Kirchhoff, V. W. J. H., Posny, F., Coetzee, G. J. R., Hoegger, B., Kawakami, S., Ogawa, T., Fortuin, J. P. F., and Kelder, H. M.: Southern Hemisphere Additional Ozonesondes (SHADOZ) 1998-2000 tropical ozone climatology 2. Tropospheric variability and the zonal wave-one, J. Geophys. Res., 108, 8241, doi:10.1029/2002JD002241, 2003.

Worden, H. M., Logan, J. A., Worden, J. R., Beer, R., Bowman, K., Clough, S. A., Eldering, A., Fisher, B. M., Gunson, M. R., Herman, R. L., Kulawik, S. S., Lampel, M. C., Luo, M., Megretskaia, I. A., Osterman, G. B., and Shephard, M. W.: Comparisons of Tropospheric Emission Spectrometer (TES) ozone profiles to ozonesondes: Methods and initial results, J. Geophys. Res., 112, D03309, doi:10.1029/2006JD007258, 2007.

Zhang, L., Jacob, D. J., Liu, X., Logan, J. A., Chance, K., Eldering, A., and Bojkov, B. R.: Intercomparison methods for satellite measurements of atmospheric composition: application to tro- 
pospheric ozone from TES and OMI, Atmos. Chem. Phys., 10, 4725-4739, doi:10.5194/acp-10-4725-2010, 2010.

Ziemke, J. R., Chandra, S., Duncan, B. N., Schoeberl, M. R., Torres, O., Damon, M. R., and Bhartia, P. K.: Recent biomass burning in the tropics and related changes in tropospheric ozone, Geophys. Res. Lett., 36, L15819, doi:10.1029/2009GL039303, 2009. 